\title{
Configurações
}

Revista Ciências Sociais

$14 \mid 2014$

Para além da Governação. Políticas, práticas e discursos de inclusão e promoção da diversidade cultural

\section{La imagen de la mujer inmigrante en los libros de texto argentinos}

A imagem da mulher imigrante nos livros de texto argentinos

Immigrant women's image in Argentinean textbooks

\section{María Soledad Balsas}

\section{OpenEdition}

1 Journals

Edición electrónica

URL: http://journals.openedition.org/configuracoes/2326

DOI: 10.4000/configuracoes.2326

ISSN: $2182-7419$

Editor

Centro de Investigação em Ciências Sociais

\section{Edición impresa}

Paginación: 151-175

ISBN: 1646-5075

ISSN: 1646-5075

\section{Referencia electrónica}

María Soledad Balsas, "La imagen de la mujer inmigrante en los libros de texto argentinos »,

Configurações [En línea], 14 | 2014, Publicado el 30 marzo 2015, consultado el 10 diciembre 2020.

URL : http://journals.openedition.org/configuracoes/2326 ; DOI : https://doi.org/10.4000/

configuracoes. 2326

Este documento fue generado automáticamente el 10 diciembre 2020.

(c) $\mathrm{CICS}$ 


\title{
La imagen de la mujer inmigrante en los libros de texto argentinos
}

\author{
A imagem da mulher imigrante nos livros de texto argentinos \\ Immigrant women's image in Argentinean textbooks
}

María Soledad Balsas

\section{Introducción}

1 En el marco de la teoría económica neoclásica que conceptualiza los movimientos de población en términos de la redistribución geográfica de los excedentes de fuerza de trabajo, las migraciones internacionales hacia la Argentina han sido históricamente presentadas como una empresa masculina. En función de su ocupación en actividades menos relevantes para la economía agroexportadora, la presencia femenina fuera de las migraciones familiares es poco valorada y, en algunos casos, hasta desalentada ${ }^{1}$. Si bien se han producidos algunos avances en las últimas décadas, este relato continuaría -aunque con connotaciones diversas- todavía vigente en la actualidad.

2 A continuación, presentaré evidencias -temáticas, retóricas y enunciativas- que permiten ilustrar estas afirmaciones. Las mismas fueron extraídas de los libros comprados por el Ministerio de Educación de la Nación para ser distribuidos en el marco de los programas compensatorios implementados entre 1993 y 2008. Se trata de 74 libros de Ciencias Sociales para el segundo ciclo del nivel primario correspondientes a Aique (22), A-z (12), Kapelusz (22) y Santillana (18), empresas líderes dentro del mercado local. En primer lugar, describiré los aspectos teóricos. Luego, reseñaré los antecedentes, haré una breve caracterización de los principales grupos de mujeres migrantes en Argentina y abordaré las cuestiones metodológicas. Para finalizar, esbozaré algunas conclusiones y perspectivas. 


\section{Migración y género: aspectos teóricos}

3 Hasta la segunda mitad del siglo pasado, la perspectiva hegemónica adoptada en los estudios migratorios se basaba sobre criterios androcéntricos según los cuales la participación de las mujeres en las migraciones se reducía a un rol pasivo de acompañante:

[s]e ha criticado a la teoría neoclásica y del equilibrio por no considerar 1 heterogeneidad de las mujeres migrantes en términos de clase, ciclo de vida y orígenes culturales, por ejemplo, o por reducir el matrimonio a una variable independiente más. Además, la explicación neoclásica supone que hombres y mujeres migran por el mismo motivo: la búsqueda de una rentabilidad económica más elevada [...]. [L]a teoría de la modernización es en buena medida responsable de que a la mujer se le asigne un rol secundario en los procesos migratorios. Los hombres serían el factor dinámico de los desplazamientos; las mujeres, solo acompañantes, y se da por supuesto que no realizan labores productivas. (Martínez Pizarro, 2008: 264)

4 La feminización de los flujos migratorios a partir de la década de 1960 a nivel internacional, por un lado, y la creciente participación de las migrantes como pioneras en los flujos, por otro, propiciaron el cambio de paradigma (Mallimaci, 2011).

5 Al tomar el hogar, entre otros, como unidad de análisis, la nueva economía de las migraciones se presenta como una alternativa más satisfactoria para dar cuenta del género. Más que como estrategia de acumulación de capital, las migraciones internacionales son entendidas dentro de este modelo como estrategia de minimización de los riesgos que amenazan la producción o el consumo en los mercados de trabajo, seguros, capital o crédito. Así pues, ante el deterioro del bienestar económico familiar, los actores diversifican la asignación de recursos mediante la localización de mano de obra de diversos miembros en mercados de trabajo geográficamente diferenciados y/o la combinación de formas de empleo locales e internacionales. Aquí la importancia de las remesas resulta clave (Massey et al., 1998).

6 La teoría del mercado de trabajo segmentado constituye otra opción válida para abordar las cuestiones de género en las migraciones internacionales. Ésta hace referencia a la necesidad de las economías modernas de atraer trabajadores dispuestos a aceptar salarios más bajos. Así, el trabajo de "subsistencia" o en pequeñas actividades mercantiles que aporta la mujer permite compensar el bajo nivel de ingresos salariales de estructuras familiares que precisan de la colaboración de todos sus miembros. En otras ocasiones, su reclutamiento masivo tiene la función deliberada de garantizar bajos niveles de remuneración. De manera similar, la etnificación de la fuerza de trabajo hace posible la existencia de una jerarquía de profesiones y remuneraciones que varía de acuerdo a las necesidades específicas de la economía en cuestión (Wallerstein, 1991). Esta teoría permite explicar, verbigracia, el surgimiento de una "cadena internacional de cuidados" en respuesta a la demanda de trabajo reproductivo en aquellos países en los que el estado de bienestar no logra satisfacerla.

7 Sin embargo, ambas teorías resultan inapropiadas para explicar los movimientos producidos por motivos diversos a los económicos. Tal es el caso de la migración altamente calificada en la que el salario no es con frecuencia el factor determinante (Martínez Pizarro 2008). Las migraciones causadas por persecución, intolerancia o desigualdad jurídica que afectan a homosexuales, transexuales y transgéneros es otro 
claro ejemplo de los límites que estas propuestas teóricas presentan para abordar las cuestiones de género en las migraciones.

\section{Antecedentes}

En un estudio pionero sobre las relaciones de género en los libros de lectura para la educación primaria durante el siglo XX, Wainerman y Heredia (1999) observan que la inmutable distribución sobre base biológica que consagra al hombre en actividades productivas y/o públicas y confina a la mujer al ámbito doméstico y reproductivo comienza a ceder recién a partir de la década de los ochenta. En los noventa, las imagen de la mujer que trabaja, incluso en tareas calificadas, se consolida junto con la del hombre que ejerce su paternidad, la domesticidad o trabaja en actividades otrora exclusivamente femeninas como la docencia.

Más recientemente, Caggiano (2012) problematiza la enseñanza de posiciones sociales desiguales en términos de "raza", género y clase social en tres manuales escolares de Ciencias Sociales para el segundo ciclo de la ex Educación General Básica. Según argumenta, la exclusión de la mujer blanca = argentina de las relaciones interraciales durante el período colonial lleva implícita la idea de la pureza genética. Su asociación a la ciudad, la familia tipo de clase media y el trabajo intelectual contrasta con la ruralidad, el exotismo y el trabajo manual de las no blancas $==$ extranjeras.

\section{Mujeres migrantes en Argentina}

10 De acuerdo con los datos del último censo, las paraguayas constituyen el grupo más numeroso de mujeres nacidas en el exterior:

Tabla 1.

Principales países de mujeres nacidas en el exterior. Censo 2010

\begin{tabular}{|c|c|c|c|}
\hline & PAÍ́S & TOTAL MUJERES & TOTAL \\
\hline $1^{\circ}$ & Paraguay & 306434 & 550713 \\
\hline $2^{\circ}$ & Bolivia & 173779 & 345272 \\
\hline $3^{\circ}$ & Chile & 102174 & 191147 \\
\hline $4^{\circ}$ & Perú & 86615 & 157514 \\
\hline $5^{\circ}$ & Italia & 82478 & 147499 \\
\hline $6^{\circ}$ & España & 53593 & 94030 \\
\hline
\end{tabular}

FUENTE: ELABORACIÓn PROPIA SOBRE DATOS DEL INSTITUTO NACIONAL DE ESTADÍSTICA Y CENSOS.

11 De proveniencia diversa, se concentran en el Gran Buenos Aires. Por lo general, migran solas, a edades tempranas, antes de tener hijos, con niveles educativos medio-bajos y por causas que exceden las económicas. Las redes femeninas de asistencia resultan de importancia estratégica no sólo para insertarse en destino sino también, en caso de tenerla, para el cuidado de la prole en Paraguay (Gaudio, 2012a, 2012b, 2011, 2009).

Aunque su presencia en Argentina es de larga data (Cerrutti y Gaudio, 2010), el servicio doméstico y el cuidado de personas ${ }^{2}$ representan su principal ocupación: 
[...] la alta frecuencia de las que trabajan en hogares particulares teniendo una estadía en el país de más de 15 años $(49,2 \%)$ indica que esta actividad no es sólo una alternativa transitoria de primer empleo, sino que tiende a ser una inserción estructuralmente permanente (Bruno, 2011: 12). ambulantes. Tal es el caso, por ejemplo, de las "paseras" que llegan cotidianamente a Posadas por vía terrestre o en lancha (Linares, 2010). En cambio, los hombres se desempeñan mayormente en: a) ocupaciones ligadas a la construcción; b) actividades que requieren cierta calificación como carpinteros, mecánicos, chapistas, electricistas y operarios en el sector textil y del calzado; c) el comercio formal e informal como dueños o empleados y d) en el sector de protección y vigilancia (Cerrutti y Bruno, 2006).

El segundo grupo más numeroso de mujeres extranjeras es representado por las bolivianas. Tradicionalmente, su presencia en la migración -excepto en la zona de frontera- ha sido reducida (Cerrutti, 2010). Sin embargo, según los datos del último censo, la distribución por sexos entre los migrantes bolivianos resulta menos desequilibrada. Un rasgo distintivo es el desplazamiento como parte de una estrategia asociativa de carácter familiar. Sin embargo, esto no supone un rol pasivo (Magliano, 2013; 2007). Si bien el trabajo del varón -en la construcción, la agricultura y la fabricación de ladrillos- orienta el proceso migratorio, la intervención de la mujer es reconocida como central para el éxito -económico pero también emocional- del proyecto migratorio (Magliano, 2013; Mallimaci, 2011).

TABLA 2.

Porcentaje de mujeres nacidas en el exterior por país de origen. Censo 2010

\begin{tabular}{|c|c|c|c|c|}
\hline & País & Total & Total mujeres & Porcentaje mujeres \\
\hline $1^{\circ}$ & Brasil & 41330 & 23907 & 57,84 \\
\hline $2^{\circ}$ & España & 94030 & 53593 & 56,99 \\
\hline $3^{\circ}$ & Italia & 147499 & 82478 & 55,91 \\
\hline $4^{\circ}$ & Paraguay & 550713 & 306434 & 55,54 \\
\hline $5^{\circ}$ & Perú & 157514 & 86615 & 54,98 \\
\hline $6^{\circ}$ & Alemania & 8416 & 4527 & 53,79 \\
\hline $7^{\circ}$ & Chile & 191147 & 102174 & 53,45 \\
\hline $8^{\circ}$ & Uruguay & 116592 & 61106 & 52,41 \\
\hline $9^{\circ}$ & Japón & 4036 & 2092 & 51,83 \\
\hline $10^{\circ}$ & Bolivia & 345272 & 173779 & 50,33 \\
\hline $11^{\circ}$ & Taiwán & 2875 & 1440 & 50,08 \\
\hline $12^{\circ}$ & Corea & 7321 & 3650 & 49,85 \\
\hline $13^{\circ}$ & Francia & 6995 & 3482 & 49,77 \\
\hline $14^{\circ}$ & China & 8929 & 4032 & 45,15 \\
\hline
\end{tabular}

FUENTE: ELABORACIÓN PROPIA SOBRE DATOS DEL INSTITUTO NACIONAL DE ESTADÍSTICA Y CENSOS.

A la vez que recaen sobre ellas las tareas domésticas y de reproducción social y cultural tales como la enseñanza de la lengua de origen, el manejo de la dieta, la introducción en 
actividades étnicas y la intermediación con la sociedad receptora, se incorporan al mercado de trabajo a través del comercio, las tareas agrícolas, los hornos de ladrillo, las actividades textiles e incluso la pesca (González, 2012). A diferencia de otros grupos, observan una menor participación en el trabajo doméstico asalariado (Benencia y Karasik citados por Buccafusca y Serulnicoff, 2005). Su desempeño laboral varía de acuerdo a la edad, el estado civil, la pertenencia de clase y el tiempo de permanencia (Magliano, 2013).

A pesar de tratarse de una corriente prácticamente estancada, las chilenas constituyen el tercer grupo más numeroso de inmigrantes residentes en Argentina. Distinto de lo que ocurre con los varones en las provincias patagónicas -Alto Valle de Río Negro y Neuquén-, las mujeres predominan, en especial a partir de la década de los noventa, en Mendoza y la Ciudad Autónoma de Buenos Aires (Matossian, 2006), donde la importancia numérica del colectivo chileno es menor con respecto a otros grupos (Cacopardo, 2005). Si bien en su conjunto presentan estructuras de edad envejecidas, las proporciones cambian en función de las áreas de localización (Cerrutti, 2009). En Buenos Aires, la llegada en las últimas décadas de jóvenes profesionales y/o universitarios atraídos por el menor costo de la educación superior podría estar incidiendo en este sentido (Jensen y Perret, 2011). A pesar del aumento de la migración calificada, el nivel de educación de los y las migrantes provenientes de Chile en Argentina resulta ser el más bajo respecto al resto de los países en los que residen (Zavala San Martín y Rojas Venegas, 2005); la mayoría cuenta sólo con el nivel primario completo. Mientras los hombres se emplean en la construcción, el comercio, la industria manufacturera, la agricultura y la ganadería, para las mujeres el servicio doméstico, seguido del comercio y las actividades agrícolas, proporciona la principal fuente de empleo (Cerrutti, 2009). Cualquiera sea su situación laboral y el nivel de instrucción alcanzado, las mujeres siguen siendo responsables de la crianza de los hijos y de las tareas domésticas, aunque a mayor nivel educativo, mejores posibilidades de negociación (Stang, 2006).

Tal como muestra la tabla 3, la inmigración peruana fue hasta la década de los noventa predominantemente masculina:

Tabla 3.

Población nacida en Perú por sexos. Censos 1980-2010

\begin{tabular}{|l|c|c|c|c|}
\hline & 1980 & 1991 & 2001 & 2010 \\
\hline Varones & 5688 & 9462 & 35871 & 70899 \\
\hline Mujeres & 2873 & 6477 & 52389 & 86615 \\
\hline Total & 8561 & 15939 & 88260 & 157514 \\
\hline
\end{tabular}

FUENTE: ELABORACIÓN PROPIA SOBRE DATOS DEL INSTITUTO NACIONAL DE ESTADÍSTICA Y CENSOS.

18 A partir de 1992, Argentina se convirtió en un destino accesible para las peruanas de clase media urbana que -aunque calificadas- se insertaron generalmente como trabajadoras domésticas y, en menor medida, como vendedoras ambulantes en el Área Metropolitana de Buenos Aires (Cerrutti y Bruno, 2006). El cambio en el patrón de género fue favorecido por la creciente demanda de mano de obra barata y sumisa y el deterioro del empleo masculino. Si bien la ocupación en actividades domésticas ofrece una rápida inserción laboral y permite financiar la educación de los hijos en el origen y la migración a largo plazo hacia otros destinos, la experiencia migratoria significó una pérdida de estatus social y una movilidad descendente (Paerregaard, 2007). "Esta situación se debe menos al 
logro educativo, el número de años de estudios o a las cualificaciones de las mujeres que a dinámicas específicas de producción y reproducción de desigualdades de género, etnicidad y clase" (Izaguirre, Anderson y Glade, 2012: 29). Al respecto, Rosas (2010) destaca la importante presencia de jóvenes en edad laboral empleados en tareas que no coinciden con el alto nivel de escolaridad alcanzado, que llegaron a Argentina movidos por el deseo (incumplido) de continuar sus estudios. Aunque dicha situación es compartida por ambos sexos, la inserción de los varones en ocupaciones con calificación técnica o profesional resultó, en general, más satisfactoria y presentó comparativamente mayores posibilidades de mejora (Cerrutti y Bruno, 2006).

19 A pesar de ser el quinto grupo más numeroso, la atención parcial históricamente dedicada a la migración de italianas ha sido justificada por la escasa consistencia numérica del fenómeno (Bruno, 2009). El índice de masculinidad del censo de 1869 parece sustentar dicha interpretación. Sin embargo, durante la década de 1870 los peninsulares tienden a emigrar en familia. Más aún, las estadísticas oficiales indican que en la década siguiente el número de mujeres y niños siguió en aumento. En los años noventa el índice de masculinidad se mantuvo casi inalterado. En 1895, había 159 hombres por cada 100 mujeres. Sólo entre 1901 y 1913, vuelven a predominar los hombres adultos jóvenes. Según el censo de 1914, había 172 hombres por cada 100 mujeres (Devoto, 2006). Si bien estos datos dan cuenta de diversas realidades, la idea de migración asociativa que subyace no permiten captar la experiencia de aquellas mujeres que viajan solas o acompañadas de otras mujeres, como las obreras especializadas en la manufactura de toscanos traídas a inicios del siglo XX por empresarios de origen italiano (Lobato, 2009), ni su diversidad profesional ni de clase (Rosa, 2013).

En la segunda posguerra, el componente femenino experimenta un crecimiento sostenido motivado por la política de reunificación familiar implementada por el gobierno peronista. Petrini (2013) y Bruno (2009) coinciden en señalar una falta de autonomía generalizada de las mujeres en la decisión de partir durante este período. Algunos de los motivos evidenciados son: la dependencia económica del grupo familiar, las decisiones parentales que buscaban preservar la pureza y la integridad femenina ante la eventualidad de una nueva ocupación extranjera, las imposiciones maritales y las presiones de la familia política ya emigrada. Pero también se hace evidente la influencia ejercida sobre los cónyuges a fin de interrumpir proyectos migratorios individuales y las migraciones voluntarias por amor. Además de emplearse en fábricas, las italianas se ocupan como modistas en grandes sastrerías o por cuenta propia, en actividades comerciales o bien permanecen al cuidado del hogar y las tradiciones familiares. Con frecuencia, después del matrimonio y/o del nacimiento del primer hijo el trabajo asalariado de la mujer resulta complementario dentro de la economía familiar.

21 Si bien los llamados familiares y los matrimonios por poder marcan cierta continuidad con el tradicional rol asignado a la mujer dentro de la familia por el fascismo, según Scarzanella (2005) el peronismo no sólo brindó a las migrantes la oportunidad de trabajar en las fábricas ${ }^{3}$ y de contar con servicios sociales sino también de militar políticamente. Sin embargo, la solidaridad étnica femenina resultó más eficaz que el estado benefactor peronista para, verbigracia, conciliar las obligaciones laborales y familiares. Aunque se abren nuevos espacios de sociabilidad por fuera de las asociaciones étnicas y la Iglesia escuelas, clubes, unidades básicas, la Fundación Eva Perón, el Partido Peronista Femenino-, la política y el sindicato siguen siendo, según Lobato (2009), un territorio 
hostil para las extranjeras. Por tal motivo, podría considerarse que el modo a través del cual el peronismo interpeló a las migrante resulta ambiguo.

Al igual que las italianas, la elevada presencia femenina entre españoles registrada en el último censo se debe, por un lado, al envejecimiento del grupo, $\mathrm{y}$, por el otro, a la mayor expectativa de vida de las mujeres (Cacopardo, 2005). A pesar de las trabas legales y consuetudinarias vigentes entre 1882 y 1926, las españolas emigran en una elevada proporción; los índices de masculinidad de la corriente española hacia Argentina son muy bajos en relación con otros destinos.

Se trata en su mayoría de mujeres solteras -en particular a partir de 1919-, en edad laboral y con un grado de alfabetización más bajo que el masculino. Excepto entre 1889 y 1892, estos datos ponen en evidencia la menor representación alcanzada por la emigración conjunta de familias (Rodríguez Galdo, 2002). Dentro de este cuadro, es posible reconocer significativas diferencias regionales. Aunque fueron relativamente pocas las gallegas que participaron en la migración ultramarina durante el siglo XIX, su participación fue en aumento a partir de la Gran Guerra. Las gallegas migran para reagruparse con su familia y/o incorporarse al mercado de trabajo como empleadas domésticas, costureras, obreras en la industria alimenticia, tabacalera, fosforera y del calzado. En cambio, las comerciantes y propietarias de tiendas eran generalmente viudas. Hacia 1952, el número de mujeres superó al de hombres (Farias, 2010).

Tal como se desprende de la Tabla 2, la presencia de chinas, coreanas y taiwanesas en Argentina es considerablemente más reducida con respecto a la de latinoamericanas y europeas. Excepto en el caso taiwanés, su participación en la migración, aunque elevada, resulta minoritaria en relación al componente masculino. La inmigración coreana a la Argentina se inició en 1965 con el objetivo de establecerse en colonias agrícolas (Mera, $2010 ; 1998)$. A partir de la segunda mitad de la década de los ochenta, su llegada se tornó masiva. Durante los noventa, la colectividad experimentó una significativa disminución cuantitativa debido a la ausencia de nuevos flujos -sólo se registran casos aislados de reagrupamiento familiar- y las expulsiones causadas por la recesión económica (Mera 2003). Este período coincide con el arribo más sistemático de contingentes provenientes de Taiwán y China.

Causada por la profundización de la inestabilidad en los países africanos occidentales y las políticas restrictivas implementadas en varios países europeos, la corriente migratoria proveniente de Senegal, Nigeria, Sierra Leona y Ghana y, en menor medida, Malí, Liberia y Guinea se incrementó en la última década (Zubrzycki et al., 2010). De los 2738 africanos registrados en 2010, 1825 eran hombres y 913, mujeres. Las africanas llegan a la Argentina junto con sus cónyuges o parientes o para reunirse con ellos (Maffia y Zubrzycki en prensa).

\section{Aspectos metodológicos}

26 La perspectiva elegida para analizar cómo operan las estrategias de visualización de la mujer migrante utilizadas en los libros de texto escolares argentinos es la del Análisis del Discurso. Dentro de éste, es posible reconocer dos grandes orientaciones. Basada en análisis críticos, socioculturales, sociológicos y/o históricos, la primera hace referencia a hábitos de pensamiento, percepción y comportamiento reflejados en textos pertenecientes a diferentes géneros. Dentro de esta tradición, el énfasis está puesto en las 
prácticas sociales, registrándose un escaso -o incluso nulo- interés por los textos en el más estrecho sentido lingüístico (Bourdieu, 1990). La segunda orientación conjuga aportes del estructuralismo francés, la etnografía de la comunicación, la lingüística funcional, la filosofía y la pragmática (Verón, 2004; van Dijk, 1993, 2001). En este contexto, se asume que ambas orientaciones pueden resultar complementarias.

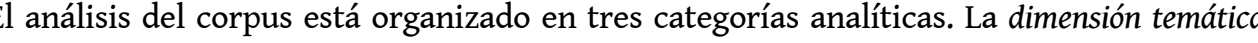
alude a las realidades culturales sobre las que se construye la materia de un discurso. Desde este punto de vista, el libro de texto escolar incluye una multiplicidad de cuestiones susceptibles de ser abordadas a partir de él. No obstante, dicha vastedad no es azarosa: el recorte que el libro de texto propone está ligado al poder y la autoridad; es el resultado de un proceso de selección que legitima determinados conocimientos en detrimento de otros. Dicha selección tiene su origen, por lo general, en la normativa curricular, expresión de los conocimientos considerados socialmente válidos en un momento histórico determinado.

La dimensión retórica incluye los mecanismos a partir de las cuales se hace visible determinada configuración del sentido en un texto. Las construcciones figuradas del lenguaje, por ejemplo, hacen referencia a aquellas operaciones discursivas que rompen con la neutralidad del lenguaje en su grado cero. No se limitan a las acciones de ornamento, aditamento o embellecimiento a las que con frecuencia se las asocia (Grupo $\mu$, 1981). Constituye un ámbito privilegiado para el análisis de las opciones ideológicas presentes en el texto (de Man, 1996). En segundo lugar, las operaciones intertextuales aluden al conjunto de relaciones entre textos o tipos de textos. En términos de Bajtín (1999), el enunciado es un mosaico en el que interactúan diferentes voces, una matriz abierta, híbrida e incompleta que está en diálogo permanente con otros textos. Además de poesías, cartas y cuentos, los libros de texto incluyen historietas, chistes, adivinanzas, trabalenguas, canciones, e-mails, entrevistas, textos de divulgación científica, informes y artículos de opinión. Entre los géneros visuales, es posible encontrar mapas, símbolos, retratos, dibujos, obras de arte, fotografías, comics, collages, organizadores gráficos y viñetas, entre otros. Las imágenes juegan un papel decisivo en "las formas en que percibimos e interpretamos pertenencias y exclusiones, formas de la diferencia y de la desigualdad" (Caggiano, 2012: 24). Los modos de mirar y de ver son enseñados y aprendidos socialmente según una lógica particular que supone anteojeras específicas ${ }^{4}$.

La dimensión enunciativa implica considerar la relación dialógica entre un yo, que se asume como locutor en el acto mismo de apropiación individual del aparato formal de la lengua, y un tú, definido como un alocutario (Benveniste, 1999). Se trata de entidades discursivas y no de sujetos empíricos. Siguiendo a Verón (1999), en los libros de texto escolares es posible reconocer seis entidades enunciativas: el enunciador-autor (presenta temas, relata episodios y dialoga con el lector), el enunciador-maestro y el enunciador-padre (fi guras derivadas), el enunciador-niño (voz del propio lector), el destinatario-niño (a quien va dirigido el acto del discurso) y el destinatario-maestro (indicaciones técnicas para el docente).

Con todo, el libro de texto es considerado en el marco del presente trabajo como un material didáctico curricular que, mediante la combinación de diversos modos semióticos, presenta en una extensión determinada y de forma secuenciada una selección de temas. Su especificidad reside en un tipo de discurso instruccional orientado a que su destinatario adquiera un conjunto de saberes considerados socialmente legítimos en el marco de la práctica escolar. 


\section{Análisis del corpus}

\subsection{Rasgos temáticos} una estrategia asociativa en la que al hombre, por lo general, le corresponde la iniciativa:

[m]i nombre es Giacomo Testa, nací [...] en Milán [...]. La situación en mi patria era muy difícil por la dura crisis económica. Por eso decidí venir a Sudamérica: me dijeron que aquí hay grandes posibilidades de progreso. Viajé sin mi familia. Cuando esté establecido y haya juntado unos pesos, los mandaré a buscar. Hoy es 13 de febrero de 1901 [...]. (Iaies y Segal, 1993: 109; mi subrayado)

[m] uchos de los inmigrantes llegados a la Argentina lo hicieron en cadena, es decir primeron [sic] llegaba al país algún inmigrante, generalmente un hombre joven y soltero o sin su esposa. Una vez ubicado en algún conventillo o pieza de alquiler y con trabajo, podía mandar a buscar a su esposa, en caso de tenerla, o a algún familiar o amigo del pueblo de origen [...]. (Tauber 2008: 200; cursiva original; mi subrayado)

[...] Antes de los seis años don Simeón envió los pasajes a su mujer, la que en el vapor "Europa" se embarcó con sus hijos Blanca, Amelia [...], Julia, Genoveva y Teodoro [...]. (Fernández Moreno citado por Skilton, 1995: 120-121; mi subrayado) Soy Carmen, un gallega de Orense, España. Tengo 19 años y me encontraré con Manuel, mi marido, que dejó la aldea para escapar de la pobreza. [...] (Castro et al., 2004: 104; cursiva original; mi subrayado)

[...] Tenía 22 años y llegué [desde Galicia] con mi marido y mi suegra el día 12 de enero de 1949 [...]. (Sampedro citado por Bustinza et al., 2004: 215; mi subrayado) [m] is padres eran yugoslavos, padre montenegrino y madre croata. Mi padre llegó a Uruguay solo, mi madre, en cambio, llegó con sus padres y sus hermanos. Se conocieron en el año 1928 y ese mismo año se casaron. Tuvieron dos hijas uruguayas y dos hijos argentinos. En agosto de 1933 viajamos a la Argentina [...]. (Elena Eracovich citada por Barros, 1995: 32; mi subrayado)

Como se pone en evidencia en las citas anteriores, este modo de concebir las migraciones femeninas no hace distinción entre flujos de diversa proveniencia ni período histórico.

Así pues, el reconocimiento de proyectos migratorios independientes resulta excepcional:

[e]l "Galileo" llevaba mil seiscientos pasajeros de tercera clase, de los cuales más de cuatroscientos eran mujeres y niños [...]. El mayor número de las mujeres llevaba consigo la familia; pero otras muchas iban solas o acompañadas de una amiga; y entre éstas, varias de la Liguria, que emigraban en busca de servicio como cocineras o camareras; otras en busca de marido, animadas por la menor concurrencia con que tendrían que luchar en el Nuevo Mundo... [...]. (De Amicis citado por Pucci, 1988; mi subrayado)

[...] María nació en una zona rural de Bolivia. Hasta los cuarenta años hizo todo tipo de trabajos agrícolas. En 1974 decidió migrar a Tilcara, en la provincia de Jujuy. Allí vive con su hijo y sus nietos [...]. Charo nació en Arequipa, Perú. Vino a nuestro país para estudiar en la universidad [...]. (Barraza et al., 2004: 72; mi subrayado)

[los inmigrantes eran] en su mayoría hombres solos, muchos jóvenes apenas adolescentes, mujeres, y algunas familias que tenían la suerte de poder viajar unidas [...]. (Cibotti, 1998: 30; mi subrayado)

La situación es compartida por mujeres pertenecientes a épocas y colectivos diversos.

Dentro de la familia migrante, el rol de la mujer parece ser inmutable y circunscripto a la reproducción biológica, el cuidado de los hijos y la gestión del hogar: 
[...] A principios del siglo XX, con la inmigración, se incorporó a la población del país una importante cantidad de mujeres en edad de tener hijos. Se calcula que el promedio de hijos por mujer era mayor a tres en la década de 1950 y que, actualmente, ese promedio se encuentra entre dos y tres hijos. (Carrozza et al., 2004: 19)

De madres a hijas, las mujeres de la chacra aprenden y ayudan a mantener la familia. (Bertoncello et al., 2007: 55)

[...] No hay descanso, terminamos con el dulce y los orejones, seguimos con la conserva de tomates, las gallinas y la huerta: chauchas y choclos en verano, acelga, zanahorias y repollo en invierno. Mi marido, mi hija, la comida, lavar, planchar y encima la leña. - Hija, es la vida de la chacra, en la familia cada cual hace su parte [...]. (Bertoncello et al., 2007: 55; mis subrayados) subjetividad. Dentro de este contexto, el caso peruano constituye un quiebre discursivo: [...] Es habitual que las mujeres dejen sus hijos pequeños en Perú al cuidado de las abuelas y que les envíen remesas [...]. (Blanco et al., 2008: 206)

37 A pesar de la alusión a las remesas, las transformaciones en las relaciones de género producto de la migración no son generalmente tratadas.

En líneas generales, su desempeño laboral es fijado a tareas muy próximas a su desempeño doméstico con escasas posibilidades de movilidad social ascendente:

[1]as mujeres inmigrantes debieron trabajar tan duramente como los hombres. Una posibilidad de empleo era trabajar como nodrizas, es decir, proveyendo de su leche para la crianza de los niños de las familias más ricas. (Barros, 1996: 105; cursiva original; mi subrayado).

[A] las mujeres que arribaron a la Argentina en los años cuarenta [...] les esperaba un conventillo, un trabajo como sirvienta y el aprendizaje de los nuevos códigos sociales [...]. (Sampedro citado por Bustinza et al., 2004: 215; mi subrayado)

[...] Las mujeres eran lavanderas o planchadoras. Sus hijos e hijas podían convertirse en obreros de alguna fábrica. [...] Recién los nietos recibían suficiente educación y capacitación para subir un escalón o dos en la sociedad [...]. (Geli y Prisley, 1997: 132; mi subrayado)

Salvo contadísimas excepciones, su rol de obrera así como su activismo político resultan comparativamente menos evidentes.

En caso de ser reconocida, su participación en el mercado de trabajo es representada en virtud de tareas informales y/o de menor calificación con respecto a los hombres:

[...] Acá nos profesionalizamos, el agricultor paraguayo aquí se hace pintor de obra, azulejista, electricista, maestro mayor de obra, profesional del calzado en las distintas ramas, costureros y se hacen profesionales muy competentes, muy codiciados. Las mujeres se dedican en su mayoría al servicio doméstico y, otras, a peluquería, enfermería y costura. (Alonso et al., 2007: 136; cursiva original)

[...] La familia Sánchez [...] llegó a la Argentina en 1910. [...] viajaron en barco desde España. En nuestro país [e]l señor Sánchez se empleó como mozo en una fonda [...] donde su esposa era cocinera, y sus dos hijas mayores, mucama y niñera [...]. (Ruibal y Piccolini, 1994: 88-89)

En todas las épocas, las migrantes altamente calificadas están completamente invisibilizadas.

Con frecuencia, el casamiento es sinónimo de trayectorias laborales truncas:

[...] A los 13 años empecé a trabajar en una "fábrica" [...]. Cuando me casé, dejé de trabajar. Mi marido, Manuel, también era gallego [...]. (Alonso et al., 1999: 28; mi subrayado) 
Juan Manuel y su esposa María [...] viven en un campo de la Patagonia. [...] Juan Manuel [...] conoció a su esposa en Chile, país de nacimiento de María. Actualmente ella ha dejado de trabajar para dedicarse a sus hijos y a las tareas del hogar [...]. (Del Río y López 2007: 73; mi subrayado) Esto resulta particularmente evidente a través del uso expresivo del blanco y negro y el sepia. Dentro de este contexto, las migrantes europeas hacen su aparición principalmente en relación a la familia, el viaje en barco y el desembarco, la vida en el conventillo, el hotel de inmigrantes y el trabajo rural. En relación a las escenas familiares, el género privilegiado es el retrato. En él nunca aparecen solas sino acompañadas de otros 
miembros. Durante el viaje, es común que las mujeres estén paradas o asomadas a la barandilla del barco junto a hombres. Pero en el desembarco se las muestra solas cargando valijas, bultos y niños. Con frecuencia, son retratadas con ropas ajadas y un pañuelo en la cabeza que funciona como ícono de su supuesta condición de campesina. La seriedad es el sentimiento más visible en sus rostros. En el Hotel de Inmigrantes, su actitud es de espera y pasividad. En una oportunidad, se las muestra en una clase de quehaceres domésticos que data de 1912. En el conventillo es posible reconocerlas entre una multitud de niños realizando tareas domésticas. El trabajo rural es ilustrado mediante fotografías de mujeres en la colonia o recolectando cereales.

En cambio, los desplazamientos que tienen como protagonistas a migrantes latinoamericanas son ilustrados principalmente mediante fotografías a cuatro colores. Esta decisión llevaría implícita la idea (errónea) de una corriente migratoria más reciente. Además del viaje y el desempeño en actividades agrícolas, las migrantes latinoamericanas son fotografiadas en la calle, en puestos de venta ambulante, por lo general de verduras, la línea de montaje y la administración pública. En este último caso, se advierte cierta posición asimétrica en relación a la empleada pública de tez blanca que, emplazada detrás de un escritorio, funciona como contrafigura. Dicha asimetría se pone también de manifiesto entre fotógrafo/a y fotografiado/a. Por ejemplo, entre las migrantes que miran a cámara es posible advertir una evidente actitud de esceptismo y/o incredulidad. A diferencia de sus pares europeas, aparecen viajando solas o bien acompañadas de otras mujeres por vía terrestre. Sólo en una ocasión se observa el desembarco de un grupo de mujeres que cruzan en lancha la frontera argentinoparaguaya. Excepto en el caso de una mujer joven "boliviana en la zafra tucumana" (Blanco et al., 2008: 205), que carga un bebé en su espalda, las migrantes latinoamericanas son menos mostradas junto a su prole.

Entre las escasas fotografías protagonizadas por mujeres asiáticas, destaca una tomada desde un plano general que muestra el interior de lo que podría ser un jardín de infantes. Un grupo de niños pequeños -todos de rasgos orientales- realizan actividades sobre mesas bajas. La única adulta es una mujer, también de rasgos orientales, que sujeta el cabello de una niña mientras la peina. El epígrafe expresa: “[...] en la década del 80, un gran número de personas de origen coreano se radicó sobre todo en la Capital Federal" (Tobío et al., 2007: 39; cursiva original). La visibilización de las migrantes asiáticas también se logra a partir de: a) una fotografía de una "ceremonia del té en un matrimonio coreano" (Bustinza y Loray, 1997: 214; cursiva original); b) otra de una mujer joven ocupada en una tarea manual; y c) una mujer con delantal parada frente a un puesto de una feria callejera adornado al estilo oriental. Ninguna mira a cámara.

51 Si se tiene en cuenta que no abundan las referencias -visuales o escritas- que permitan vincular la presencia africana con la Argentina contemporánea, no resulta extraño que no se incluyan fotografías de mujeres de dicho origen. En este caso, se privilegian las litografías de César Bacle. La litografía constituye una técnica prácticamente en desuso en la actualidad que resulta de utilidad para fijar la presencia de africanos/as con el pasado colonial.

Los organizadores gráficos que presentan datos estadísticos son utilizados por lo general para ejemplificar el predominio masculino. Este recurso se utiliza llamativamente sólo para el período comprendido entre la segunda mitad del siglo XIX y las primeras décadas del XX. Por ejemplo, mediante un gráfico de barras extraído de la Enciclopedia Mi país, tu país se compara la cantidad de inmigrantes por sexo desde 1871 hasta 1920. A partir de estos datos, se interroga "¿[q]ué conclusiones sacas sobre la relación entre el ingreso de 
hombres y mujeres?" (Schuster, 1994: 23). En otro gráfico de características similares el porcentaje de varones entre 1857 y 1929 asciende al setenta por ciento. Además, se precisa que eran prevalentemente jóvenes, solteros, italianos o españoles (Palermo y Califa, 1995).

Las referencias al discurso pictórico incluyen una reproducción de "El emigrante" de Llimona. El mismo es protagonizado por un hombre joven parado en el centro de un bote. Su mirada está perdida en el vacío. Detrás de él, sentado, otro hombre, mayor, sostiene con sus manos dos remos. Delante del hombre joven, una mujer en el piso, que sostiene un bebé con su brazo derecho, duerme. En el cuadro "La sopa de los pobres" de Giudici también se observa a una mujer joven de rostro triste, sentada en el centro, con un bebé en brazos. Frente a ella, un anciano sostiene un plato con su mano derecha. A la izquierda de la mujer, una niña pequeña permanece de pie. Un hombre con sombrero come de un plato. Hacia el fondo, ollas humeantes. En tercer lugar, en "Sobre el puente del barco" de Ribéra dos mujeres y tres hombres vestidos de época están en el pasillo de un barco. Por último, en "Los emigrantes" de Tommasi un conjunto de hombres, mujeres y niños en la dársena de un puerto esperan ser embarcados. Apenas distinguibles, una mujer embarazada y otra que está dando el pecho a un bebé. Cabe destacar que en todos los casos se trata de artistas masculinos europeos; no hay referencias a obras de pintoras ni de pintores de otras nacionalidades.

En cuanto al discurso literario, es de interés el "Poema para el esfuerzo gringo":

[e]n el pródigo vientre de esta tierra, / hombres de muchas patrias / procrean su destino. / Tenaces como hormigas en la dura faena / que no tiene domingos.../ Gauchos rubios más guapos que los de la leyenda, / que empuñan el arado, más noble que el cuchillo... / Cuentan en la guitarra sus ternuras y penas, / sin descuidar las trojes, los pámpanos y el lino. / Su noble afán colmó de espigas la carreta / y abrió sobre los campos la fl or de los molinos. / Apacentó el ganado, levantó la vivienda / y nos hizo el regalo múltiple de sus hijos. / Ésta es la pampa nueva, / gran colmena de América para el esfuerzo gringo. / Ya no es la pampa grande que cantó Santos Vega, / pero es la pampa rica donde germina el trigo... (del Pozo citado por Skilton, 1995: 122; mi subrayado)

Nótese el uso de metáforas biológicas que exaltan el aporte demográfico realizado por los inmigrantes europeos en el ámbito de la economía agroexportadora. Si bien el poema se centra en la fi gura masculina, en la imagen del vientre, la procreación y la prole está implícita la participación de la mujer. "La gringa" de Sánchez y "El conventillo de la paloma" de Vaccarezza son otras de las obras citadas que tematizan el rol de la mujer de origen migrante en la sociedad. No se registran alusiones al discurso normativo, histórico o actual, ni al discurso académico, no obstante los avances producidos, en clave de género.

En relación a los medios masivos de comunicación, un "dibujo aparecido en 'La Ilustración Sudamericana' (Bustinza y Loray, 1995: 158; cursiva original) que muestra el perfil de hombres y mujeres parados frente a la barandilla de un barco.

\subsection{Rasgos enunciativos}

57 En primer lugar, el enunciador-autor, presumiblemente masculino y de orígenes europeos, cede eventualmente su voz a migrantes que narran sus historias de vida en primera persona:

"No olvido que la primera imagen que tuve de Buenos Aires fue un pan blanco tirado en la basura. Tenía 22 años y llegué con mi marido y mi suegra el día 12 de 
enero de 1949" -cuenta Purificación Martínez-. "Era un día de muchísimo calor y durante el viaje en taxi hasta Avellaneda [...] veía tachos en las veredas con tanta comida tirada que no lo podía creer. Pensé que había llegado al paraíso. Allá en Galicia comíamos pan negro. Veníamos del hambre y el racionamiento [...]" (Sampedro citado por Bustinza et al., 2004: 215; mi subrayado)

- Celsa, vamos a necesitar más leña -dijo doña Angelina [...]. - No hay descanso, terminamos con el dulce y los orejones, seguimos con la conserva de tomates, las gallinas y la huerta: chauchas y choclos en verano, acelga, zanahorias y repollo en invierno. Mi marido, mi hija, la comida, lavar, planchar y encima la leña. - Hija, es la vida de la chacra, en la familia cada cual hace su parte. Es la única manera de mejorar, con esfuerzo, hacer lo más posible en casa, tenerla ordenada y ahorrar. Pero acá nunca faltó comida, no como en mi pueblo, cerca de Nápoles. Cuando llegamos, no había nada; nosotros hicimos todo: construimos las acequias, plantamos los álamos y los primeros manzanos. (...) Ahora ya tenemos nuestra tierra y la casa. (Bertoncello et al., 2007: 55; mi subrayado)

[m] is padres eran yugoslavos, padre montenegrino y madre croata. Mi padre llegó a Uruguay solo, mi madre, en cambio, llegó con sus padres y sus hermanos. Se conocieron en el año 1928 y ese mismo año se casaron. Tuvieron dos hijas uruguayas y dos hijos argentinos. En agosto de 1933 viajamos a la Argentina. [...] A veces me pregunto: ¿cuál fue la mayor frustración? ¿El idioma? El servocroata, lengua que se habla en Yugoslavia, es sumamente difícil, no tiene nada que ver con el castellano [...]. (Elena Eracovich citada por Barros, 1995: 32; mi subrayado)

Si bien en ocasiones también cede su voz a migrantes varones provenientes de países limítrofes, no ocurre lo mismo con las mujeres del mismo origen:

El motivo de venir a la Argentina es familiar. Estoy hace 10 años acá. Trabajo en un estacionamiento. Desde que llegué, empecé a trabajar. Lo que me gusta acá es la parte de medicina, te atienden muy rápido, cosa que allá no hay, y es todo pagar y pagar, acá no, es gratuito. Lo que no me gusta es que, cuando llegué, había mucho racismo. En la calle, te dicen eh, boliviano, no me molesta para nada, soy boliviano y no me ofende. (Blanco et al., 2008: 207)

Me trajeron para trabajar en un taller de costura clandestino. No sabía, pero me exigían que trabajara a la fuerza. Todos los gastos que hizo la señora para traerme a Buenos Aires, tenía que devolvérselos. Hacíamos remeras, y me pagaban por remera 15 centavos. Trabajaba de ocho de la mañana a doce de la noche. Estaba cansado, cansado... Jamás había trabajado así en mi vida. Los propios bolivianos traen a la gente a que trabajen 16 horas y pagan muy poco. (Blanco et al., 2008: 207)

Sus experiencias y sentimientos tienden a ser narradas por el mismo enunciador-autor:

María nació en una zona rural de Bolivia. Hasta los cuarenta años hizo todo tipo de trabajos agrícolas. En 1974 decidió migrar a Tilcara, en la provincia de Jujuy. Allí vive con su hijo y sus nietos [...]. Charo nació en Arequipa, Perú. Vino a nuestro país para estudiar en la universidad [...]. (Barraza et al., 2004: 72)

[1]a venta en puestos callejeros de verduras y especias resulta una alternativa para muchas inmigrantes (Tobío et al., 2007: 9; cursiva original)

[...] Muchos de los trabajadores inmigrantes no tienen más posibilidades que trabajar en actividades en las que el pago en negro está muy difundido: gran parte de las mujeres se emplean como trabajadoras domésticas en casas de familia [...]. (Tobío et al., 2007: 19)

60 Así, la voz de las latinoamericanas, aunque también de las asiáticas y africanas, está ausente.

En segundo lugar, el enunciador-maestro es personificado a través de ambos sexos:

[maestra:] "[1]a Argentina de hoy es, en parte, el resultado de esa mezcla de pueblos y culturas. Nuestros apellidos, costumbres, comidas y deportes están vinculados con 
las personas que llegaron hace muchos años al país desde distintas partes del mundo. [...]" (Castro et al., 2004: 105; cursiva original)

[profesor:] "[l]a población del país cambia. Aumenta por los chicos que nacen y las personas que vienen de otros países a vivir aquí, y disminuye por las personas que mueren y las que se van a vivir a otros países." (Fariña et al., 2006: 33) destinatario-niño a través del nosotros inclusivo. Asimismo, éste es interpelado como descendiente de inmigrantes, en particular de origen europeo, mediante consignas dirigidas a averiguar la historia familiar, realizar un árbol genealógico, etc. En este contexto, la etimología del apellido -paterno-deviene un significante clave no sólo de la propia identidad sino también de la pretendida distinción con respecto a otros grupos:

[...] Entrevista a algún familiar tuyo de origen europeo. Averigua el origen de tu apellido; ¿Qué significado tiene? ¿En qué año llegó tu familiar [...] a la Argentina? ¿Qué medio de transporte utilizó? ¿En qué lugar del país se radicó? ¿Qué trabajos hizo? ¿Dónde vivía? ¿En qué tipo de edificio? ¿Por qué se fue de su país de origen? [...]. (Kapelusz, 1991: 117; mi subrayado)

Listen los apellidos de todos los compañeros e indiquen al lado su origen ¿De qué nacionalidades son los apellidos listados? ¿Qué origen predomina? ¿Cuál aparece en segundo lugar? ¿En qué año llegó al país el mayor número de inmigrantes? ¿Cuál era su nacionalidad o el grupo de nacionalidades? [...]. ¿La información del cuadro concuerda con las proporciones de apellidos de los alumnos del grado? [...]. (Schuster, 1994: 26)

[d]oy por supuesto que mi apellido les dice algo sobre mi historia personal. Soy el bisnieto de Ernesto Tornquist, que fue el hijo del fundador de la familia en la Argentina. Jorge Tornquist llegó a Buenos Aires en 1823 y, entre otros negocios, tenía un barco en The British Packet and Argentine News [...]. (Alonso et al., 1999: 27; cursiva original)

No hay marcas que den cuenta de su filiación materna.

\section{Conclusiones y perspectivas}

Si se tienen en cuenta los cambios registrados en las últimas décadas a nivel mundial no sólo en los estudios migratorios sino también en los modos de presentación de las cuestiones relativas al género en los libros de textos escolares, llama la atención la vigencia que la etnificación de las relaciones de género y clase tiene en los textos 
escolares argentinos. En este sentido, podría argumentarse que la imagen social de la mujer inmigrante en los libros analizados contribuye a (re)producir una visión ideológicamente sesgada. Parafraseando a Wainerman (2003), los libros escolares argentinos repiten ad nauseam una perenne división sexual del trabajo migrante que adquiere matices diversos según el país de proveniencia.

Dentro de un discurso hegemónico que valora las migraciones en términos de aporte demográfico, destaca la visión instrumental del supuesto rol biológico de las europeas. Sobre esta base, se postula el origen europeo de la argentinidad. Las migraciones protagonizadas por mujeres latinoamericanas, en cambio, son más proclives a ser representadas en términos independientes en el marco de la teoría de los mercados de trabajo segmentados. Lo observado se torna particularmente evidente a partir de los textos visuales. Las migrantes asiáticas y africanas están comparativamente menos visibilizadas.

A diferencia de las mujeres argentinas, las migrantes politizadas y/o altamente calificadas -como Sofía Mendoza, Ester de Izaguirre, Lita Pérez Cáceres, Rosa Palma Gutiérrez, Eugenia Sacerdote, Gigliola Zecchin, Maruja Mallo, Clara Campoamor, Silvia Torrás, Araceli Vázquez Málaga, Ana María Calvente y Dolores del Olmo de Iribarne, entre otrassiguen constituyendo una realidad mayormente ignorada. Si se asume que los textos (re)crean roles y funciones desigualmente asignados, garantizando la disponibilidad necesaria para llevar a cabo las tareas peor retribuidas y menos gratificantes, dicha omisión no parece azarosa. En este sentido, es preciso comenzar por cuestionar el difundido estereotipo de la mujer migrante que la describe como una joven campesina, con bajo nivel de instrucción, que migra hacia la ciudad para emplearse en el servicio doméstico. Sólo a través del distanciamiento crítico de la arraigada etnificación de las relaciones de género y clase será posible lograr una inserción más justa y equitativa de las mujeres migrantes en la sociedad argentina.

\section{BIBLIOGRAFÍA}

ALONSO, María Ernestina; BLANCO, Jorge; BUCHBINDER, Pablo y SOLETIC, María Ángeles (2007), Ciencias Sociales 5. Serie Puntos Cardinales. Pilar: Aique.

ALONSO, María Ernestina; BLANCO, Jorge; LABANDEIRA, María Celia; SOLETIC, María Ángeles y WOSNIAK, Jorge (2007), Ciencias Sociales 6. Serie Puntos Cardinales. Pilar: Aique.

ALONSO, María Ernestina; ELISALDE, Roberto; VÁZQUEZ, Enrique; BLANCO, Jorge; CASO, Fernández, María Victoria y GUREVICH, Raquel (1999), El origen de la Europa Moderna y el Mundo Contemporáneo. Colección Sociedades y territorios en cambio. Madrid: Aique.

BAJTÍN, Mijaíl (1999), Estética de la creación verbal. México: Siglo XXI.

BARRAZA, Natalia; FARIÑA, Mabel; MAIDANA, Leda; SAGOL, Cecilia y PAVICICH, María Eugenia (2004), Ciencias Sociales 4. Colección Ideas en la Cabeza. Buenos Aires: Santillana.

BARROS, Diego (1995), Manual Aique Multiciencias 5. Buenos Aires: Aique. 
BARROS, Diego (1996b), Manual Aique Multiciencias 4 Bonaerense. Madrid: Aique.

BARROS, Diego (coord.), 1996a. Manual Aique Multiciencias 6. Buenos Aires: Aique.

BENVENISTE, Émile (1999), Problemas de lingüística general II. México: Siglo XXI.

BERTONCELLO, Rodolfo; BREVI, Perla; TAGLIAVINI, Gabriela y VIARD, Graciela (2007),

Multimanual Ciencias Sociales Neuquén. Buenos Aires: Santillana.

BLANCO, Jorge; FERNÁNDEZ CASO, María Victoria; GUREVICH, Raquel; CHAVES, Silvia; VÁZQUEZ, Enrique; ALONSO, María Ernestina; SOLETIC, María Ángeles; MAZZEO, M. y LEWKOWICZ, Mariana (2008), Ciencias Sociales 9. ConCiencia Social. Buenos Aires: Aique.

BLANCO, Jorge; FERNÁNDEZ CASO, María Victoria; GUREVICH, Raquel; VÁZQUEZ, Enrique; ALONSO, María Ernestina; SOLETIC, María Ángeles (2008), Ciencias Sociales 8. Serie ConCiencia Social. Buenos Aires: Aique.

BOURDIEU, Pierre (1990), Sociología y cultura. México DF: Grijalbo.

BRUNO, Oriana (2009) “"Le navi delle mogli»: donne calabresi in Argentina”. Altreitalie, vol. 38-39: 61-84.

BRUNO, Sebastián (2011), “Migrantes paraguayas y el servicio doméstico en Buenos Aires. Diferencias y desigualdades". Ponencia presentada en las XI Jornadas Argentinas de Estudios de Población. Neuquén, 21, 22 y 23 de septiembre.

BUCCAFUSCA, Sandra y SERULNICOFF, Myriam (2005), "Servicio doméstico en la Argentina. Condición laboral y feminización migratoria”. Ponencia presentada en el Séptimo Congreso Nacional de Estudios del Trabajo. Buenos Aires, 10, 11 y 12 de agosto.

BUSTINZA, Juan Antonio; BUSTINZA, Patricia y FRANCO, Roxana (2004), Ciencias Sociales 9. Serie Integrar. Buenos Aires: A-z.

BUSTINZA, Patricia y LORAY, María Julia (1995), Ciencias Sociales Pro-a 7 Bonaerense. Serie del alba. Buenos Aires: A-z.

BUSTINZA, Patricia y LORAY, María Julia (1997), Ciencias Sociales Pro-a 6. Colombia: A-z.

CACOPARDO, María Cristina (2005), “Acerca de las mujeres migrantes en la Argentina: tendencias y mercado de trabajo”, compilado por S. Chejter Migraciones, globalización y género en Argentina y Chile. Buenos Aires: Fundación Heirinch Böll.

CAGGIANO, Sergio (2012), El sentido común visual. Disputas en torno a género, "raza" y clase en imágenes de circulación pública. Buenos Aires: Miño y Dávila.

CARROZZA, Wilfredo; CATTARUZZA, Alejandro; DENKBERG, Ariel; DE PRIVITELLIO, Luciano; GARCÍA, Patricia; IPPÓLITO, Mónica; MINVIELLE, Sandra y RASNOSKY, Judith (2004), Ciencias Sociales 9. Santillana Hoy. Buenos Aires: Santillana.

CASTRO, Hortensia; IPPÓLITO, Mónica; LENCI, Daniel; MINVIELLE, Sandra; MOSTEIRO, María del Carmen; VIARD, Graciela; MAIDANA, Leda y PAVICICH, María Eugenia (2004), Ciencias Sociales 6. Colección Ideas en la Cabeza. Singapur: Santillana.

CERRUTTI, Marcela (2009), Diagnóstico de las poblaciones de inmigrantes en la Argentina. Buenos Aires: Dirección Nacional de Población, Ministerio del Interior.

CERRUTTI, Marcela (2010), Salud y migración internacional: mujeres bolivianas en la Argentina. Buenos Aires: Programa Naciones Unidas para el Desarrollo / Centro de Estudios de Población. 
CERRUTTI, Marcela y MAGALÍ, Gaudio (2010), “Gender differences between Mexican migration to the United States and Paraguayan migration to Argentina". The Annals of the American Accademy, vol. 630: 93-113.

CERRUTTI, Marcela y MATÍAS, Bruno (2006), “La inserción de migrantes paraguayos y peruanos en el mercado de trabajo del Área Metropolitana de Buenos Aires”. Estudios Migratorios Latinoamericanos, vol. 20, n. 60: 265-290.

CEVA, Mariela y MONTALDO, María Inés (2009), "Las mujeres italianas en el mercado de trabajo de Buenos Aires entre el fin del siglo XIX y los primeros años del XX", compilado por L. Maronese. Buenos Aires italiana. Buenos Aires: Comisión para la Preservación del Patrimonio Cultural de la Ciudad Autónoma de Buenos Aires.

CIBOTTI, Ema (1998), Ciencias Sociales Historia 8. Colombia: A-z.

DE MAN, Paul (1996), Aesthetic Ideology. Minneapolis: University of Minnesota Press.

DEL RÍO, Walter y LÓPEZ, Laura (2007), Ciencias Sociales 5. Serie del faro. Buenos Aires: Kapelusz. DEVOTO, Fernando (2006), Historia de la inmigración italiana en Argentina. Buenos Aires: Biblos.

FARÍAS, Ruy, (2010), La inmigración gallega en el sur del gran Buenos Aires: (1869-1960). Tesis de Doctorado. Santiago de Compostela: Universidad de Santiago de Compostela.

FARIÑA, Mabel; IPPÓLITO, Mónica; MINVIELLE, Sandra; SAGOL, Cecilia y SCIRICA, Elena (2006), Ciencias Sociales 5. Colección Ideas en la Cabeza. Singapur: Santillana.

GAUDIO, Magalí (2009), “Decisiones migratorias y familia entre mujeres paraguayas”. Ponencia presentada en las X Jornadas Argentina de Estudios de Población. San Fernando del Valle de Catamarca, 4,5 y 6 de noviembre.

GAUDIO, Magalí (2011), "Migración y maternidad a distancia de mujeres paraguayas en Buenos Aires, y arreglos familiares en Paraguay". Ponencia presentada en el IV Congreso de Población de la Asociación Paraguaya de Estudios de Población. Asunción, 16-18 de noviembre.

GAUDIO, Magalí (2012a), "Mujeres paraguayas en el Área Metropolitana de Buenos Aires. Decisión migratoria, relaciones familiares y maternidad a distancia". Temas de Antropología y Migración, n. 3: 40-60.

GAUDIO, Magalí (2012b), “Mujeres paraguayas y el inicio del proceso migratorio: ¿migración individual o migración familiar?". Ponencia presentada en el V Taller Paraguay desde las ciencias sociales. Asunción, 21, 22 y 23 de junio.

GELI, Patricio y PRISLEI, Leticia (1997), Sociedad, espacio, cultura. La Argentina. América Latina. Colección Realidades. Madrid: Kapelusz.

GONZÁLEZ, Myriam (2012), “Migración, género y territorio. Mujeres migrantes en una ciudad patagónica. De la invisibilidad a la presencia”. Voces en el Fénix, n. 21: 64-67.

GRUPO M. (1981), A General Rhetoric. Maryland: Johns Hopkins University Press.

IAIES, Gustavo y SEGAL, Analía (1993), Laboratorio de Ciencias Sociales 7. Buenos Aires: Aique.

INSAUSTI, Magdalena (2000), "Hotel de Inmigrantes. Un proyecto colosal para la gran Argentina”. Todo es Historia, n. 398.

IZAGUIRRE, Lorena; ANDERSON, Jeanine y OLIVER, Glade (2012), Implicancias de la migración laboral femenina peruana en las mujeres migrantes y sus familias. Lima: Fondo de Población de las Naciones Unidas / Pontifi cia Universidad Católica del Perú. 
JENSEN, Florencia y GIMENA, Perret (2011), “Migración chilena a la Argentina: entre el exilio político y la migración económica-cultural”. Sociedad \& Equidad, n. 2: 143-162.

KAPELUSZ EDITORA (1991), Manual Kapelusz 6. Quilmes: Kapelusz.

LINARES, María Dolores (2010), "Prácticas comerciales fronterizas de las mujeres paraguayas paseras en la ciudad de Posadas, Argentina”. Contribuciones Científi cas GAEA, vol. 22: 327-338.

LOBATO, Mirta (2009), “Inmigración y trabajo femenino en la Argentina de la primera mitad del siglo XX", compilado por L. Maronese. Buenos Aires italiana. Buenos Aires: Comisión para la Preservación del Patrimonio Cultural de la Ciudad Autónoma de Buenos Aires.

MAFFIA, Marta y BERNARDA, Zubrzycki (En prensa), "Desde el África subsahariana a la Argentina ¿Un incipiente corredor migratorio?”, compilado por S. Sassone. Panorama contemporáneo de las migraciones internacionales en la Argentina. Perfi les, territorios e identidades. Buenos Aires: IMHICIHUCONICET.

MAGLIANO, María José (2007), “Migración de mujeres bolivianas hacia la Argentina: cambios y continuidades en las relaciones de género". Cahiers Alhim, n. 14: 41-62.

MAGLIANO, María José (2013), “Los signifi cados de vivir múltiples presencias: mujeres bolivianas en Argentina". Migraciones internacionales, vol. 7, n. 1: 165-195.

MALLIMACI, Ana Inés (2011), “Migraciones y géneros. Formas de narrar los movimientos por parte de migrantes bolivianos/as en Argentina". Estudios Feministas, vol. 19, n. 3: 751-775.

MARTÍNEZ PIZARRO, Jorge (ed.) (2008), "La migración femenina y la migración califi cada", América Latina y el Caribe: migración internacional, derechos humanos y desarrollo. Santiago de Chile: Comisión Económica para América Latina y el Caribe.

MASSEY, Douglas; ARANGO, Joaquin; HUGO, Graeme; KOUAOUCI, Ali; PELLEGRINO, Adela y Taylor, Edward (1998), Worlds in motion. Understanding international migration at the end of the millennium. Oxford: Clarendon.

MATOSSIAN, Brenda (2006), “Migración chilena en la Argentina: aportes al análisis geodemográfi co según la encuesta complementaria de migraciones internacionales". Párrafos geográfi cos, vol. 5, n. 2: 29-60.

MERA, María Carolina (1998), La inmigración coreana en Buenos Aires. Buenos Aires: Eudeba.

MERA, María Carolina (2003), "La inmigración coreana en Buenos Aires. Historia y actualidad.” XI Congreso Internacional de la Asociación Latinoamericana de Estudios de Asia y África, Ciudad de México, 12-15 noviembre.

MERA, María Carolina (2010), "Historia de la inmigración coreana en América Latina. Refl exiones desde la situación política, económica y cultural de Corea”. Congreso Nacional de la Asociación Latinoamericana de Estudios de Asia y África, Buenos Aires, 20 y 21 de agosto.

PAERREGAARD, Karsten (2007), "La migración femenina: estrategias de sostenimiento y movilidad social entre peruanos en España y Argentina”. Anthropologica, año XXV, n. 25: 61-82.

PALERMO, Miguel Ángel y CALIFA, Oche (1995), El trébol azul 7. Madrid: Aique.

PETRINI, Flavia (2013), “Mujeres en la inmigración italiana a Buenos Aires durante la segunda posguerra: Motivos de la partida y roles de género en la sociedad de acogida", Ponencia presentada en las VII Jornadas de Jóvenes Investigadores, Instituto "Gino Germani”. Buenos Aires, 6, 7 y 8 de noviembre.

PUCCI, Julia (1988), Mensajero 7. Buenos Aires: Kapelusz. 
RODRÍGUEZ GALDO, María Xosé (2002), “Cruzando el Atlántico, ¿Solos o en familia? Migrantes españolas en las "listas de pasajeros" argentinas (1882-1926)". Historia Social, n. 42: 59-79.

ROSA, Silvia (2013), Italiane d'Argentina. Storie e memorie di un secolo d'emigrazione al femminile (1860-1960). Turín: Ananke.

ROSAS, Carolina (2010), Implicaciones mutuas entre el género y la migración. Mujeres y varones peruanos arribados a Buenos Aires entre 1990 y 2003. Buenos Aires: Eudeba.

RUIBAL, Juan y PICCOLINI, Patricia (coord.) (1994), Manual Esencial 4. Brasil: Santillana.

SAFAR, Amalia (1996), Aula Nueva 7. Madrid: Kapelusz.

SCARZANELLA, Eugenia (2005), “Extranjeras en el país de Evita: la inmigración femenina italiana a Argentina (1946-1955)”. Anuario americanista europeo, n. 3: 145-174.

SCHUSTER, Nidia (coord.) (1994), Ventana al mundo 7. San Pablo: Aique.

SKILTON, Graciela (1995), Mensajero 6. Buenos Aires: Kapelusz.

STANG, María Fernanda (2006), “Saberes de otro género. Emigración califi cada y relaciones intergenéricas en mujeres argentinas y chilenas", Informe fi nal del concurso "Migraciones y modelos de desarrollo en América Latina y el Caribe", CLACSO.

TAUBER, Ricardo (2004), Sociedad en red 9. Serie de Tramas. Buenos Aires: A-z.

TAUBER, Ricardo (2008), Sociedad en red 8. Serie de Tramas. Florida: A-z.

TOBÍO, Omar; LEVIN, Florencia; AGRATTI, Laura y WAKSMAN, Vera. 2007. Ciencias Sociales 6. Madrid: Kapelusz.

VAN DIJK (1993), “Principles of critical discourse analysis”. Discourse \& Society, n. 4: 249-283.

VAN DIJK (2001), “Critical Discourse Analysis”, compilado por D. Schiffrin; D. Tannen y H. Hamilton. The handbook of discourse analysis. Oxford: Blackwell.

VERÓN, Eliseo (1999), Esto no es un libro. Barcelona: Gedisa.

VERÓN, Eliseo (2004), Fragmentos de un tejido. Barcelona: Gedisa.

WAINERMAN, Catalina (2003), Un siglo en los libros de lectura de la escuela primaria. Serie Documentos de Trabajo $N^{\circ}$ 7. Victoria: Universidad de San Andrés.

WAINERMAN, Catalina y HEREDIA, Mariana (1999), ¿Mamá amasa la masa? Cien años en los libros de lectura de la escuela primaria. Buenos Aires: Fundación Editorial de Belgrano.

WALLERSTEIN, Immanuel (1991), “Universalismo, racismo y sexismo, tensiones ideológicas del capitalismo”, compilado por I. Wallerstein y F. Balibar. Raza, Nación y Clase. Madrid: IEPALA.

ZAVALA SAN MARTÍN, Ximena y ROJAS VENEGAS, Claudia (2005), “Globalización, procesos migratorios y estado en Chile", compilado por S. Chejter. Migraciones, globalización y género en Argentina y Chile. Buenos Aires: Fundación Heirinch Böll.

ZUBRZYCKI, Bernarda (2010), “La migración ghanesa en Buenos Aires. Una contribución a la caracterización de la presencia africana en Argentina”, compilado por L. Rodríguez de la Vega. Congreso Nacional de la Asociación Latinoamericana de Estudios de Asia y África. Buenos Aires: Mnemosyne. 


\section{NOTAS}

1. Según Insausti (2000), la categoría de mendigos incluida en el artículo 32 de la Ley de Inmigración y Colonización alcanzaba a las mujeres solas con hijos menores ya que eran consideradas inhábiles para el trabajo y susceptibles de recurrir a la beneficencia pública.

2. Bruno (2011) relativiza la relación causal entre bajo nivel de instrucción y empleo doméstico.

3. Esta afirmación contrasta con lo observado por Lobato (2009) y Ceva y Montaldo (2009), quienes sostienen que las italianas, así como las extranjeras de diversas nacionalidades, se venían empleando en Swift, Armour, The Patent Knitting Co. y la Fábrica Argentina de Alpargatas desde fi nes del siglo XIX.

4. A pesar de su evidente interés a los fines del presente trabajo, no se incluyen las imágenes referidas en el apartado dedicado al análisis del corpus debido a que la Ley 11.723 de Propiedad Intelectual vigente en Argentina no prevé la reproducción -aún con fines académicos- de textos visuales incluidos en obras protegidas.

\section{RESÚMENES}

Dentro de la narrativa hegemónica sobre las migraciones hacia la Argentina, prevalece una visión de éstas como una empresa principalmente masculina. Aunque se han producidos algunos avances en las últimas décadas, los esfuerzos para indagar las migraciones sobre las relaciones de género resultan todavía escasos. Este artículo analiza el rol de la mujer en las migraciones internacionales, según se refleja en los libros de texto de Ciencias Sociales de nivel primario publicados en Argentina en los últimos años presentan. Así sul rol surge ligado principalmente a la reproducción, el cuidado de la familia y la gestión del hogar. Dentro de un discurso dominante que valoriza las migraciones en términos de su contribución demográfica, es común hallar alusiones a mujeres migrantes que "siguen a su marido", están embarazadas, dando de mamar o rodeadas de niños. No obstante, es posible identificar valoraciones diversas según el país de proveniencia. En los casos en que se admite su participación en el mercado laboral, su imagen es fi jada con frecuencia a actividades informales, poco calificadas o muy próximas a su desempeño doméstico.

Dentro da narrativa hegemónica sobre as migrações para a Argentina, prevalece a visão de estas serem um fenómeno principalmente masculino. Ainda que se tenham produzido alguns avanços nas últimas décadas, os esforços para estudar a imigração sob uma perspetiva de género são escassos. Este artigo analisa o papel da mulher nas migrações internacionais, segundo a imagem projetada nos livros de texto de Ciências Sociais de nível primário publicados na Argentina nos últimos anos. O papel da mulher apresenta-se ligado à reprodução, ao cuidado da família e à gestão do lar. o discurso dominante valoriza as migrações em termos da sua contribuição demográfica, sendo comuns as alusões a mulheres imigrantes que "seguem o seu marido", estando grávidas, dando de mamar ou rodeadas de crianças. Não obstante, é possível identificar valorizações diferentes segundo o país de origem. Nos casos em que se admite a participação da mulher no mercado laboral, a sua imagem é associada frequentemente a atividades informais, pouco qualificadas e muito próximas do seu papel doméstico. 
The hegemonic narrative about migration to Argentina is male dominated. Although some advances have been made in recent decades, efforts to investigate migration based on a gender perspective are still scarce. This article analyzes the role of women in international migration, as reflected in textbooks in Social Science for elementary school, published in Argentina in the recent years. Mainly, women's role appears predominantly linked to the reproduction, care family and housework. Dominant discourse tends to value migration mainly in terms of their demographic contribution, finding references to migrant women as "following her husband", being pregnant, breastfeeding or surrounded by children. However, it is also possible to identify differences depending on country of origin. In cases in which participation in the labor market is recognized, the image of female immigrant worker is shown in informal activities, unskilled or closely related to their domestic performance.

ÍNDICE

Keywords: Gender, migration, Argentina, historic narratives, image

Palabras claves: Género, migraciones, narrativas históricas, imagen

Palavras-chave: migrações, imagem

\section{AUTOR}

\section{MARÍA SOLEDAD BALSAS}

CONICET, Instituto Multidisciplinario de Historia y Ciencias Humanas. Enderezo para correspondencia: Saavedra 15, $4^{\circ}$ piso, Ciudad Autónoma de Buenos Aires C.P.: C1083ACA msbalsas@conicet.gov.ar 